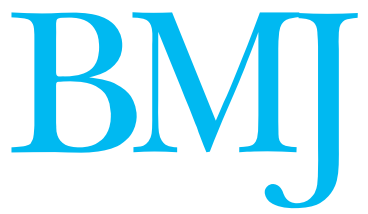

\title{
How protective is the working time directive?
}

\author{
The aim of improving workers'safety and protection has got lost in the confusion
}

See News p 310

BMJ 2004;329:301-2
$\Lambda^{1+10}$ lthough the aim of the European Working Time Directive is to improve workers' safety and protection, it seems to have caused a collective headache for member states since its conception more than 10 years ago. The resulting debates and modifications have elevated this humble headache to a full blown migraine now that the directive has been extended to include doctors in training (p 310). ${ }^{1}$

In 1993 the European commission stipulated the minimal requirements to limit working time to a maximum of 48 hours a week by November 1996. For the medical profession, this included all doctors other than doctors in training. For various reasons, the United Kingdom lagged behind and the directive was not implemented until October 1998.

As the directive stands there is only work and resting-no in between such as on-call times, when the doctor may not actually be working. The commission is also concerned about the use of opt outs, which give individuals the right to opt out of the weekly limit on working hours. Doctors may opt out for various reasons, such as the need to earn more money or to receive more training, or simply due to pressure exerted by the trust they work for. The more doctors opt out, the easier it becomes for trusts to comply with the requirements of the directive.

Last week the directive was extended to doctors in training and junior doctors, who traditionally work long hours to fulfil service and training requirements. They can no longer work more than 58 hours a week (box).

In addition to legitimate worries such as less time at work having a negative impact on doctors' training, the shortfall of doctors and consequent financial implications are immense. For example, the United Kingdom needs up to 12550 more doctors, costing up to $£ 78 \mathrm{~m}$ ( $\$ 143 \mathrm{~m} ; € 118$ ) to fulfil the requirements of the directive. Germany needs between 15000 and 27000 more doctors, costing up to $€ 1.75 \mathrm{bn}$, and the Netherlands needs 10000 more healthcare staff, costing $€ 400 \mathrm{~m}^{2}{ }^{2}$

\section{The European Working Time Directive and doctors in training}

From August 2004, doctors in training should be working an average of no more than 58 hours a week. By August 2009, this is reduced to 48 hours. Specific provisions regarding rest that must be met include:

- 11 hours' continuous rest in every 24 hour period

- A minimum 20 minute break when a shift exceeds six hours

- A minimum 24 hour rest in every seven days or minimum 48 hour rest in every 14 days.
On the positive side, the directive has made some member states, including the United Kingdom, question the way medical staff have worked. Common sense schemes have been devised, such as the hospital at night project which redefines how medical cover is provided in hospitals out of hours; (www.modern.nhs.uk/ hospitalatnight) and changing to a competency based rather than time based model of training.

On the negative side, the directive has resulted in unsocial shifts and yet another tier of bureaucracy to ensure that rotas are compliant. Also, pressure from member states has already forced the commission to review the directive, especially regarding the definition of work and rest and the further use of opt outs, threatening the safety and protection of workers. The commission began this thorough review in December 2003, gathering evidence from many different groups and sectors, and concluded that some key points needed to be reconsidered. These include the interpretation of the concept of working time, the conditions for applying opt outs, and extending reference periods to calculate the working weekly average. ${ }^{3}$ In the case of opt outs the options are to tighten the conditions for individual opt outs, to make them possible through collective agreements only, and to phase out or drop individual agreements. Ironically, the commission's proposals on these issues are imminent and could override the protection that doctors in training have had since last week.

What this means in practice is that if a third category of time is recognised-the inactive part of on-call timeresident on-call duties might be resumed. If opt outs remain, individual doctors might feel bullied into opting out for the sake of their job prospects and careers.

We could look at the lessons learnt since 1998. The 48 hour week restriction seems to have made little impact on consultants and non-consultant career grade doctors. Although the BMA believes that many consultants work more than 48 hours a week without officially opting out (BMA central consultants and specialists committee, personal communication, 30 July 2004), they do not know of any case where this has resulted in a prosecution. A recent study showed that working conditions for a quarter of non-standard grade posts conflict with the European Working Time Directive. ${ }^{4}$

Why will the situation be different for doctors in training? Although the Department of Health has

Sources of further information are on bmj.com 
worked hard to help trusts comply, ${ }^{5}$ a recent survey of 490 junior doctors shows that only a third thought that their place of work had implemented changes in order to be complaint with the directive. ${ }^{6}$ A survey conducted by the Guardian showed that about half of 75 trusts expected difficulties complying. ${ }^{7}$

The health and safety executive may impose up to $£ 5000$ for every breach and has the right to prosecute. However, it does not seem to have enough inspectors or time to enforce the legislation for the groups included since 1998. This does not bode well for doctors in training.

Where does this leave the rights of individual doctors? The BMA's junior doctors committee has produced guidelines which outline individual rights, provide samples of appropriate forms, and list the steps to take if doctors in training wish to challenge any breach of the limit on working hours. ${ }^{8}$

Doctors might also learn the lesson on the importance of collective injunctions from coal miners. In 1999 a group of coal miners took out an injunction against their employers for making them work more than 48 hours a week in order to keep mines open. On the advice of their union, they refused to sign an opt out agreement. The high court ruled in their favour and "granted a declaration that the plaintiffs [claimants] need not work until such time as their average hours fell within the statutory limits."

Unfortunately, the most likely outcome is that those who are already exploited will be further abused. Richer countries will continue to recruit from poorer ones as a quick fix to their staffing shortages, worsened by the directive. ${ }^{10}$ And as doctors in training go home to a good night's sleep or attend a training course, their (usually overseas) non-standard grade colleagues-a vulnerable group unlikely to protest against breaches of the directive, because of fears about their future job prospects- will be left holding the bleep. ${ }^{11}$

\section{Rhona MacDonald editor, Career Focus}

(rmacdonald@bmj.com)

BMA House, London WC1H 9JR

Competing interests: None declared.

1 Mayor S, Burgermeister J, Kosner K, Villanueva T, Tuffs A, Spurgeon B, et al. Over the limit? BMJ 2004:329:310.

2 Commission of the European Communities. Communication from the commission to the council, the European Parliament, the European Economic and Social committee and the Committee of the Regions. 2003. http:/ europa.eu.int/comm/employment_social/labour_law/docs/ version finale en pdf (accessed 2 Aug 2004).

3 European Commission. Second phase of consultation of the social partners at European Commission. Second phase of consultation of the social partners at
community level. May 2004. http://europa.eu.int/comm/employment social/labour_law/docs/wtd_en.pdf

4 Dosani S, Schroter S, MacDonald R, Connor J. Recruitment of doctors to non-standard grades in the NHS: analysis of job advertisements and survey of advertisers. BMJ 2003;327:961-4.

5 Department of Health. A compendium of solutions to implementing the Working Time Directive for doctors in training from August 2004. London: DoH, 2004. www.dh.gov.uk/assetRoot/04/08/26/35/04082635.pdf (accessed 2 Aug 2004).

6 British Medical Association. BMA cohort study of 1995 medical graduates. Ninth report. London: BMA, 2004.

7 Carvel J. NHS hit by crisis over doctors' hours. Guardian 2004 July 30. http://society.guardian.co.uk/NHSstaff/story/0,7991,1272457,00.html (accessed 2 Aug 2004).

8 BMA Junior Doctors Committee. Time's up 1 August 2004. A guide on the EWTD for junior doctors. June 2004. www.bma.org.uk/ap.nsf/Content/ TimesUp/\$file/TimesUp2.pdf (accessed 2 Aug 2004).

9 Barber and others (plaintiffs) v RJB Mining (UK) Ltd (defendants). IRLR $308,1999$.

10 Blair D. Britain is draining Malawi of nurses. Daily Telegraph. 2004 July 20.

11 Rapid responses to Cross P. The wall of silence. BMJ Career Focus 2003;327:s134 http://careerfocus.bmijournals.com/cgi/eletters/327/ $7421 / \mathrm{s} 134 \# 38813$

\section{How many eggs?}

\section{Ideally, one egg and one offspring}

$\mathrm{F}$ or some, the most crucial part of the question of "How many eggs?" is how many eggs one should put in the same nest. For others, it is how many can one get out of the same nest? Translate nest into incubator, and the study of Pinborg et al in this issue seems to address both. ${ }^{1}$

This is the second in a series by Pinborg et al (p 311) on the outcome of 3393 liveborn twins after in vitro fertilisation (IVF) with or without intracytoplasmatic sperm injection (ICSI) compared with 10239 liveborn control twins in Denmark between 1995 and 2000. ${ }^{12}$ The first was based on 3438 twins born after IVF and ICSI and 10362 naturally conceived twins, but dealt with the neonatal outcome of the 3393 and 10239 liveborns among them. ${ }^{2}$ The current study deals with the same 13632 (that is 3393 IVF and 10239 non IVF and ICSI) liveborn twins. It is remarkably consistent in the reporting of their neonatal outcomes, but a further control group of singletons born after IVF and ICSI is now added to complete the picture. ${ }^{1}$ Apparently we are yet to see another study, announced already, based on the same infants from the same nest but without the control twins. ${ }^{3}$

The current report along with its predecessor seems to bring a much needed positive note on the outcome of twins conceived after IVF and ICSI. ${ }^{12}$ A systematic review of controlled studies published earlier this year had shown little difference, if any, in the frequencies of (very) preterm birth, (very) low birth weight, and small size for gestational age between twins born after assisted conception and those conceived naturally. ${ }^{4}$ Unexpectedly, a lower perinatal mortality but a higher rate of neonatal admission to hospital was found among the IVF and ICSI twins. ${ }^{4}$ Pinborg et al, on a much larger cohort, seem to confirm this with a perinatal mortality (stillbirth plus deaths in first week) of 20.7 per 1000 in twins born after IVF and ICSI versus $23.4 / 1000$ in control twins. The same seems to apply to infant mortality (death within the first year after birth) with rates of $10.3 / 1000$ and $15.0 / 1000$, respectively. ${ }^{12}$ This, however, does not annihilate the fact that both death rates are substantially higher than the rates for singletons born after IVF and ICSI. ${ }^{1}$

Then, how good is the news that neurological disability, including cerebral palsy, occurs with a similar frequency among twins born after IVF and ICSI and among naturally conceived control twins? Does it help to know that the rate was statistically not different from that in singletons born after assisted conception or that low gestational age and low birth weight had a greater
Papers p 311

BMJ 2004;329:302-3 